\title{
3D MODELS FOR THE RESTORATION PROJECT: SOME ISSUES AND A CASE STUDY
}

\author{
Giuseppa Novello ${ }^{\mathrm{a}}$, Elena Marchis ${ }^{\mathrm{b}}$ \\ ${ }^{a}$ Full Professor - DISET (Department of Building Engineering and Territorial Systems) - Politecnico di Torino, \\ pina.novello@polito.it \\ ${ }^{\mathrm{b}}$ PhD student - DISET (Department of Building Engineering and Territorial Systems) - Politecnico di Torino, \\ elena.marchis@polito.it
}

\section{Commission V, WG 4}

KEY WORDS: Architecture, Representation,3D modelling, Integration of techniques, Solid image

\begin{abstract}
:
This contribute aim to explore 3D modelling and its practical applications investigating scales of representation and scales of contents. The goal of this research work was to test the flexibility of modeling tools to different field of application and to draw shared methods, even if they are applied.

During the research occurred some problems that should be considered as central for future developments. They will drive the mainlines for the refinement of software and application technologies, but it must be remembered that, first of all, the direct experience and the validation with practical case studies must be absolutely taken into account. On the basis of the outcomes and of research directions for the future, it has paved the way to thinking useful to the implementation of the method and to the management of the graphic results.
\end{abstract}

\section{INTRODUCTION}

The research is intended to investigate the active role that drafting and graphical representation have taken in building culture. A special attention has been placed focusing on the changes that have occurred recently due to the new tools offered by digital technology. Aim of the investigation is to evaluate the applicability of these methods and procedures in specific areas of building restoration, and particularly through the examination of a case-study: the yard the "Chiesa della Misericordia" in Turin, whose architectural survey started in 2008 (Figure 1).

In particular the interest of the study addressed the evaluation of the learning process and examination of some operational changes introduced in management practices, necessary to support dynamically the most appropriate choices.

Figure 1-Relief of Chiesa della Misericordia in Turin - scale 1:50

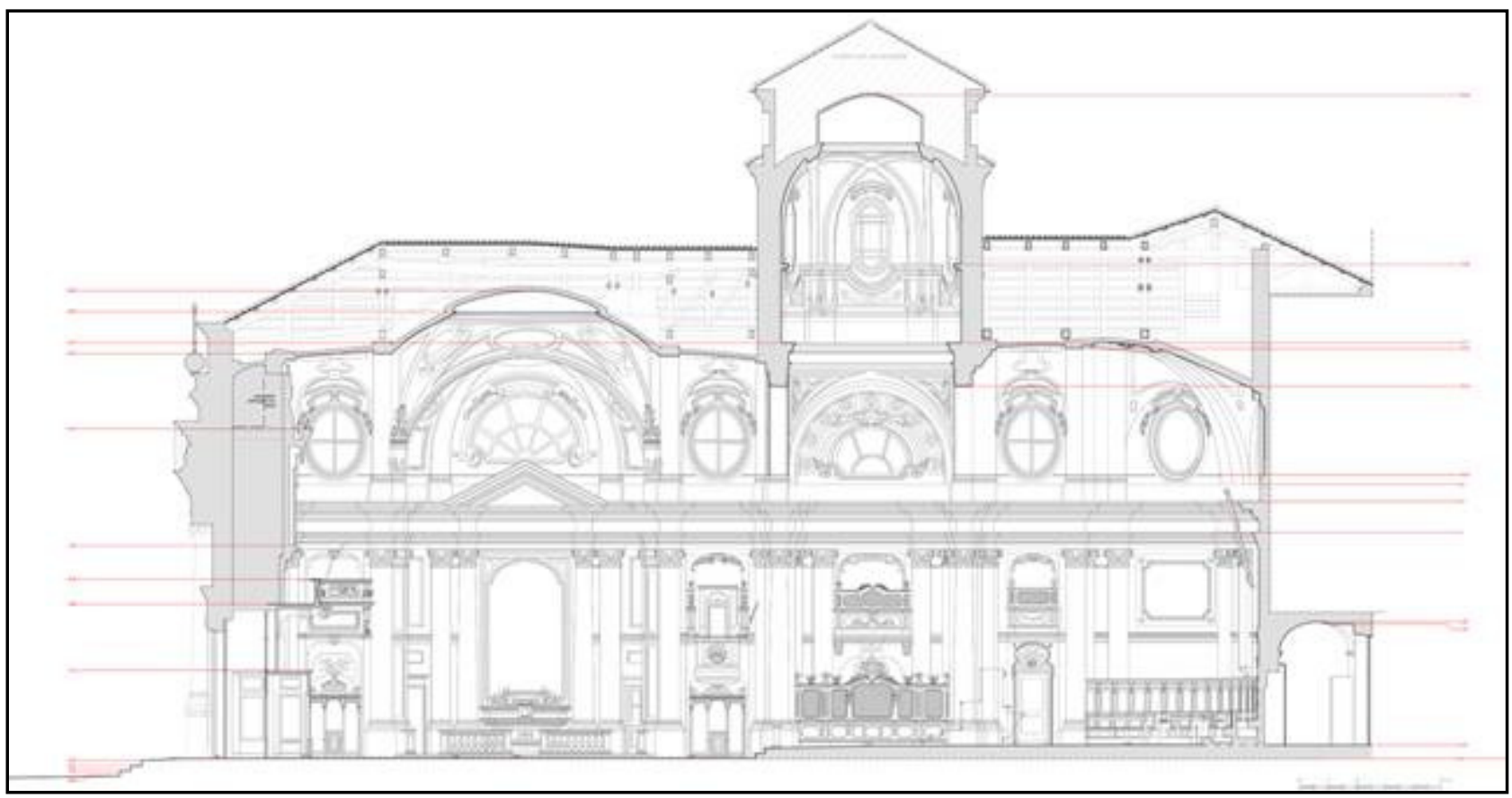


The examined alternatives are the result of a series of tests carried out to compare the traditional methods of survey drafting and the computer integrated ones, developed with the newest technological innovation: traditional, and historical, survey methods, are placed in comparison to $3 \mathrm{D}$ digital modeling in order to investigate the quality and limitations of the procedures, to discover their features (the most efficient and the less-productive), to estimate the effectiveness of the development processes, and finally the level of applicability to the architectural restoration.

The study and return numeric-graphic geometry, size and morphological characterization of the "Chiesa della Misericordia", is the base knowledge for the registration of additional thematic data, and then the support and development environment of choice for diagnostic activities, forecasting and organization of operations, in this case related to the project / process and restoration of good ecclesiastical. The use of multiple techniques, combined and integrated, is the methodological foundation of the survey conducted metric and contextual graphical depiction.

The research, conducted within the Dipartimento di Ingegneria dei Sistemi Edilizi e Territoriali (Department of Building Engineering and Territorial Systems) of the Politecnico di Torino, focuses on developing guidelines and creating a model aimed at both the simple three-dimensional representation of the complex morphology of the "cultural heritage", and the need to manage the process of restoration in all its aspects and phases: relief from the restitution of the building restored.

The importance of the project "Chiesa della Misericordia" [BocCONCINO et al., 2009], directed by Professor Secondino Coppo and conducted by a research group composed by Maurizio Bocconcino, Elena Marchis, Paolo Piumatti, Marco Vitali, was the result of different operational approaches followed in the work [Milella], [Lo Turco, Piumatti, 2006], as listed below:

- interpretation of the geometry of horizontal and vertical sections from surveying with total station supported by "eidotipi"; (Figure 3)

- tracking profiles from point cloud filtered [BONORA et al., 2004] (Figure 6);

- geometry reconstruction in vectorization of a view from the solid and the projection on lines drawn on the floor of three; (Figure 2)

- dimensional model;

- return of architectural details from direct detection techniques metric;

- redesign of the architectural [GAIANI et al., 2000] elements from digital image rectification;

- restitution of the floor plan of the plant and the time schedule and attic from ortho-rectified and the relevant direct and indirect [BONORA et al., 2006], [CHIABRANDO et al., 2008].

From the major activities it emerged the need to investigate some issues related to the three-dimensional modeling as a potential medium for subsequent restoration of the interior, which was the argument of a doctoral thesis in cultural heritage written by Elena Marchis. The creation of a three-dimensional mathematical model, implementation, consultation and assistance to the restoration sites (Figure $4-5$ ), has been the object of interest, considered in its different values and characteristics, aimed not only at the spatial-geometric description of the architectural composition, but suitable to conduct structural tests, dynamic strain displaying simplified analysis lighting, sound, etc ...

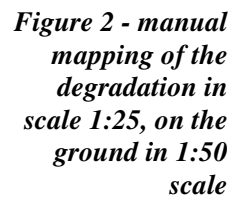

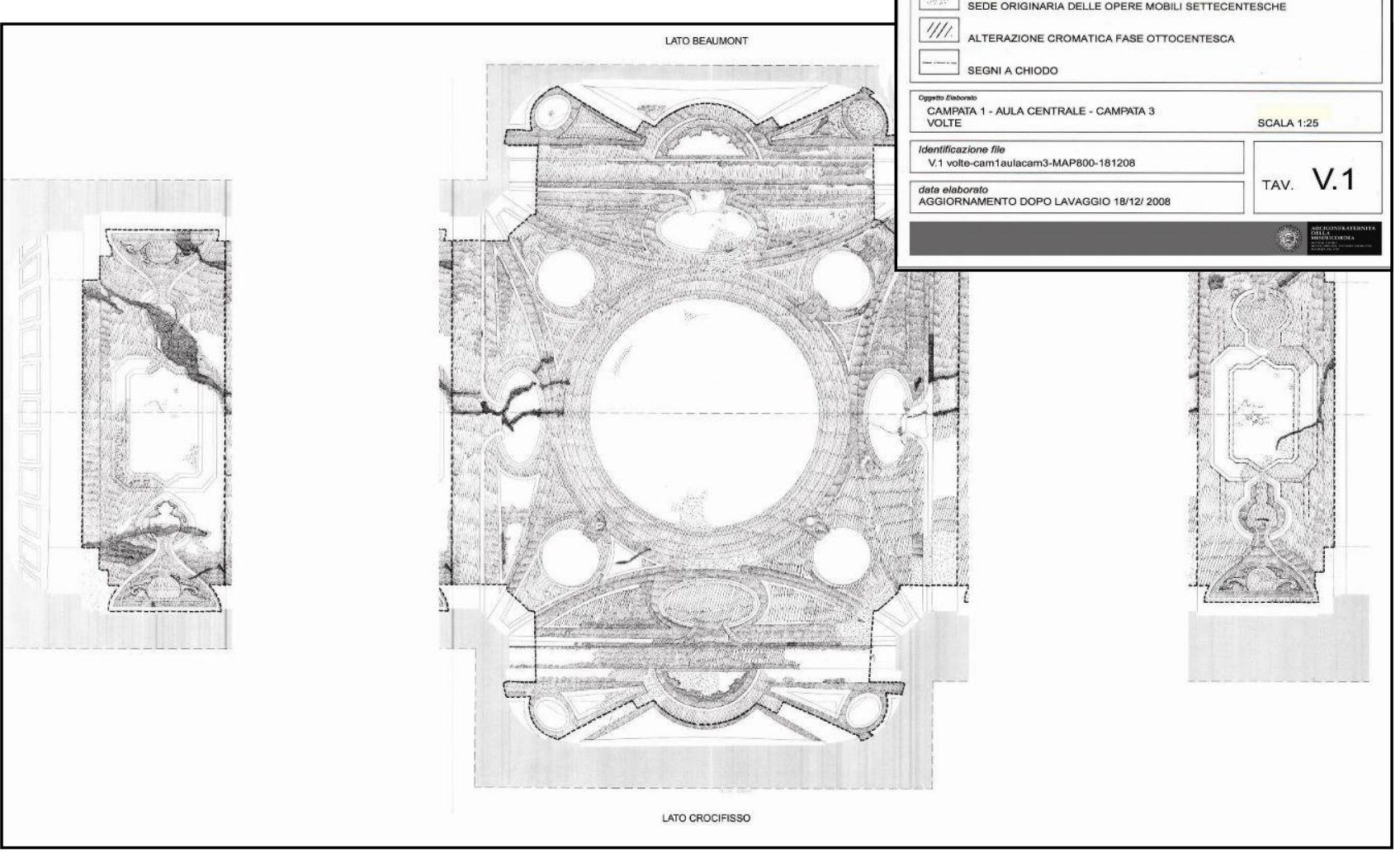




\section{RELATED WORK}

The initial idea about this software tool was to create a threedimensional mathematical model to serve as the basis for a database, and capable to assist during all operations and stages of "big" restoration sites. The data collected during the survey have been organized into a database, where data and images were not included in, but were simply connected to the grid. This aspect would not to overburden the system in reading, and so making easier the information query supported by a "light" structure of data.

In the project, this information system would be combined to a dynamic three-dimensional model, but it has not been still completed for insurgent's integration computer problems, having to interconnect different work packages. It is hoped that a future standardization of software and especially its portability and flexibility can make feasible the central idea of this research.

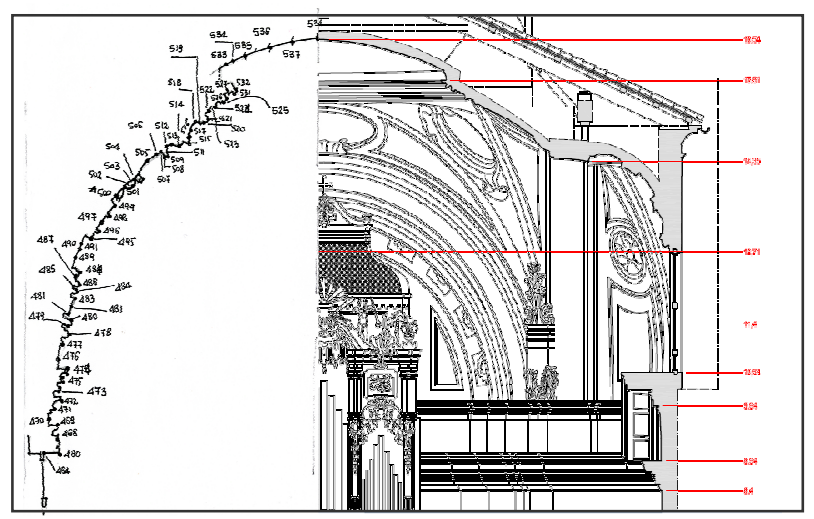

Figure 3 - Eidotype and architectonic survey

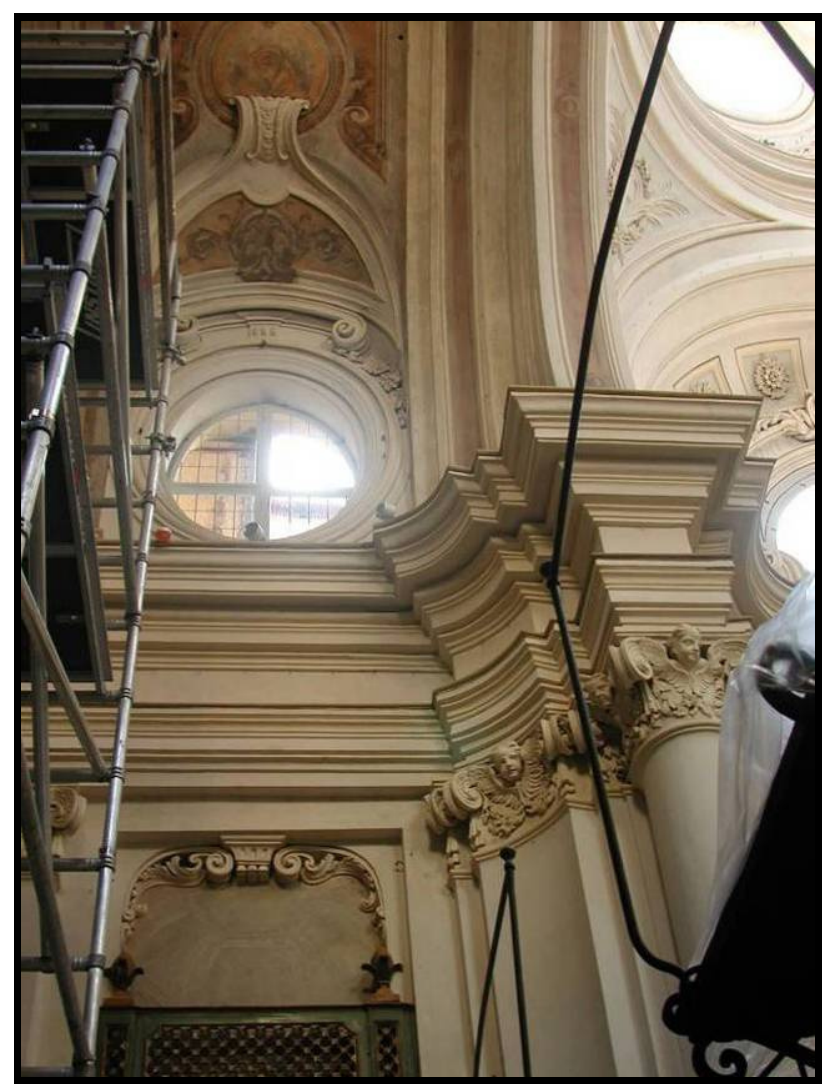

Figure 4 - Restoration site

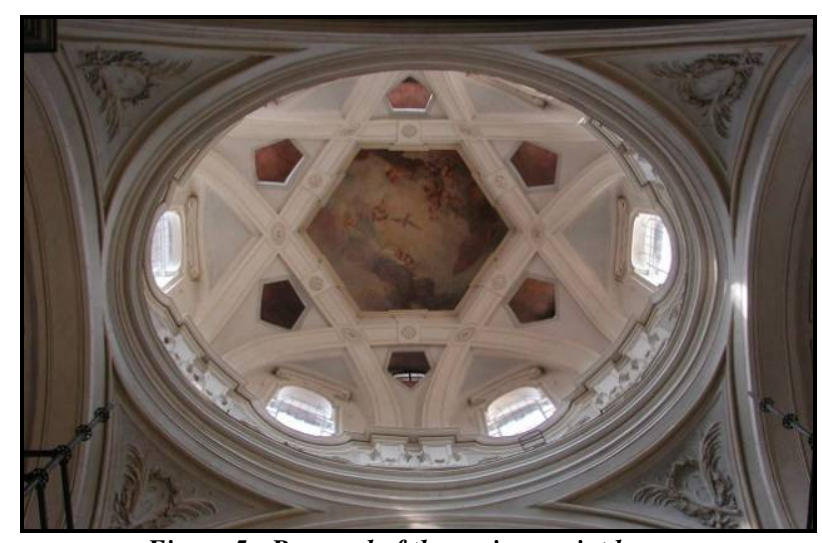

Figure 5 - Removal of the various paint layers;
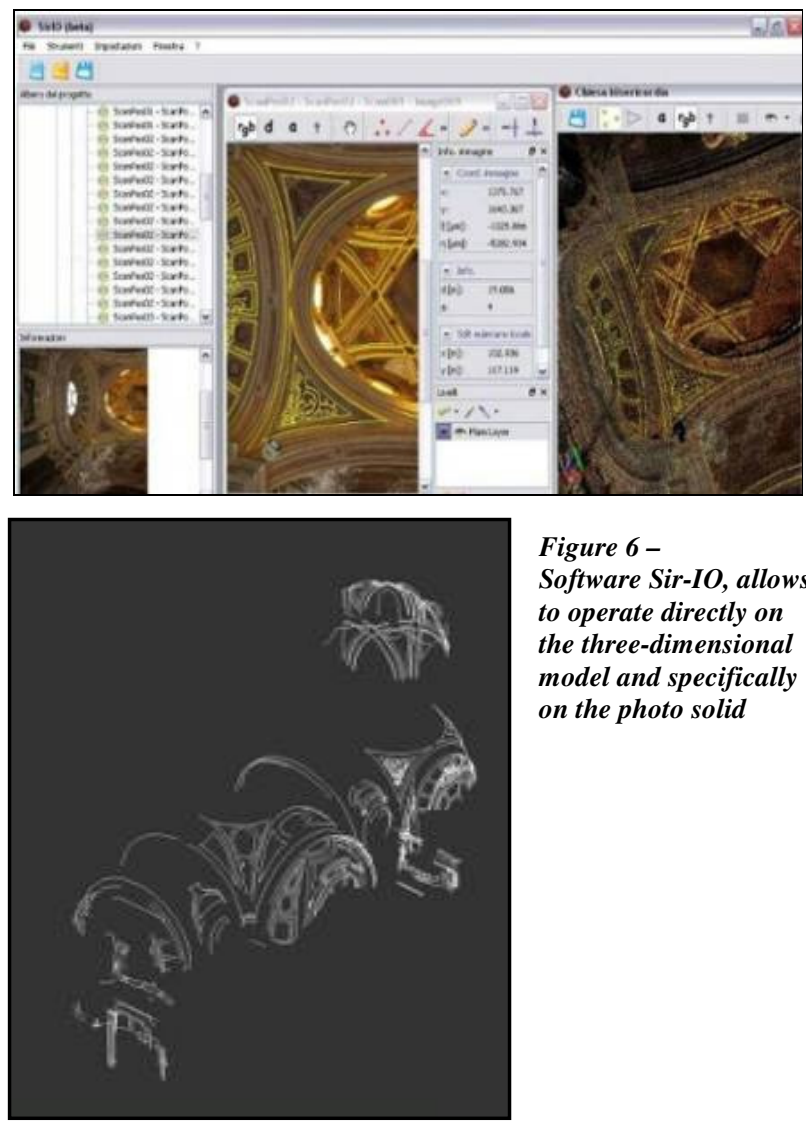

Figure 6-

Software Sir-IO, allows to operate directly on the three-dimensional model and specifically on the photo solid

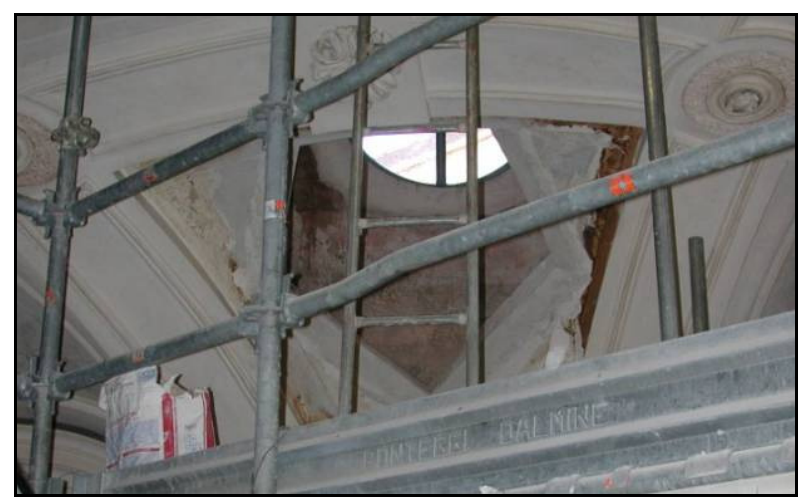

Figure 7 - Opening of the six pentagons located in the dome above the altar after the untap the paint surface 


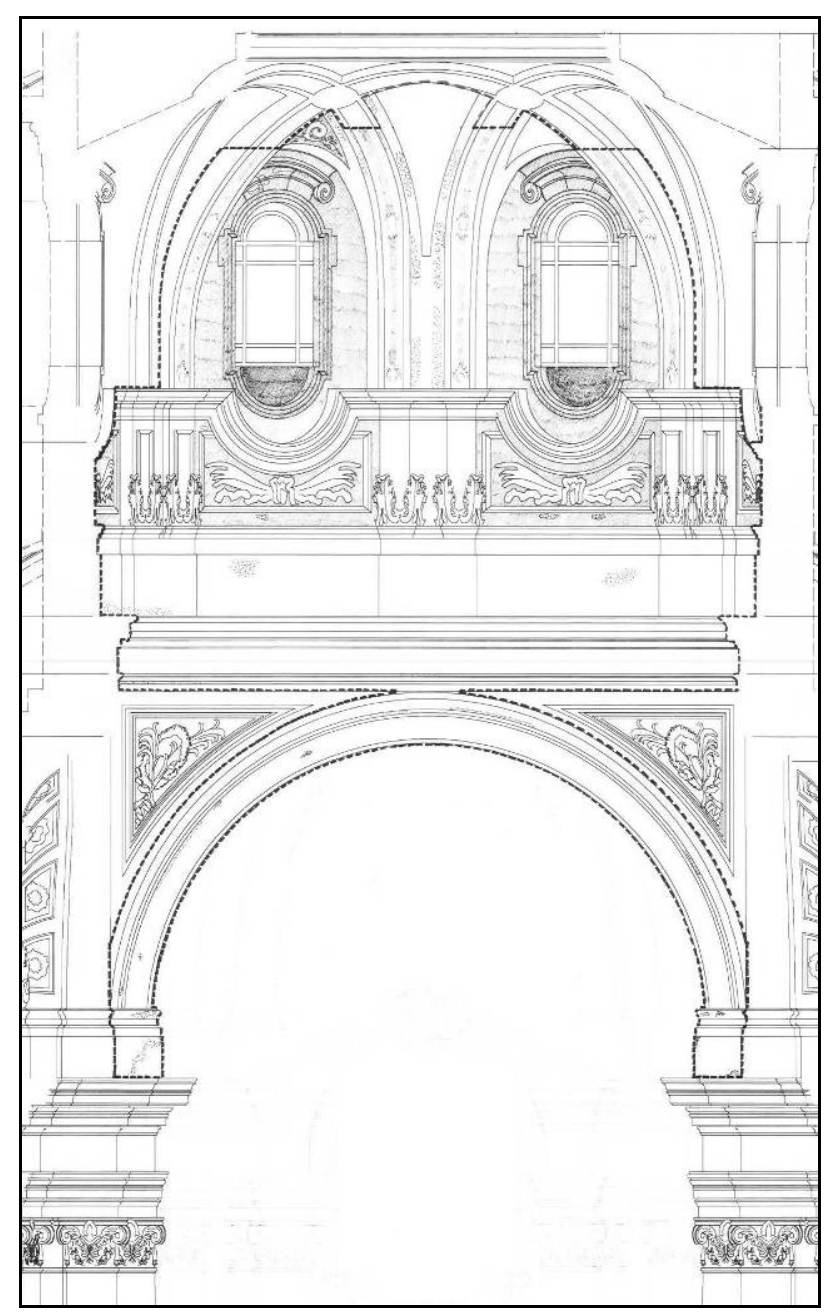

Figure 8 - Mapping of degradation on a survey drawing
The initial hypothesis was directed toward the preparation of a 3D GIS model, a local informative system, capable to be questioned at different levels of detail as required in the different research stages, but also suitable of improvements. Despite it were the most interesting and stimulating solution, already in the first steps of the research it was realized that the staff of technicians to whom refer and discuss with was not enough for supporting the initiative, and for this reason it was impossible to complete the experiment with this method.

Currently, the tools available are still unable to support and develop the mass of information contained in the point cloud, which must be very detailed in order to describe and render the representation under consideration, and especially to describe the process of acquisition of the data necessary to calculate the areas of the degraded surfaces.

The model has to be developed to serve as support to project and to compute the surface contained within a polygonal, being this a damaged area, a painted zone, or variously decorated paintings. The regions, defined by means of traditional techniques in order to project them on the model, must be vectorized [BLASI, CoISSON, 2008]. It should be paid close attention to the areas "spread" on the model so that they coincide with the real areas and that the real magnitude of the errors be acceptable. This process should be a tool to place in the $3 \mathrm{D}$ space the $2 \mathrm{D}$ mapped surfaces and to calculate the effective areas (Figure 8). To create the model we started from the point cloud which was followed by their interpolation by means of the Sir-IO software, developed for managing data geomatics [CHIABRANDO et al., 2008]. With this software it is possible to get contour lines with a pitch of $10 \mathrm{~cm}$, useful to create a "virtual surface" as close to reality as possible. (Figure 9-10). One of the main uses of this model is the mapping and quantification of the degradation of defined areas, for purposes as the accounting and the management of the yard. Such a system could be of great help to monitor and to quantify the work of craftsmen working in restoration projects and more.

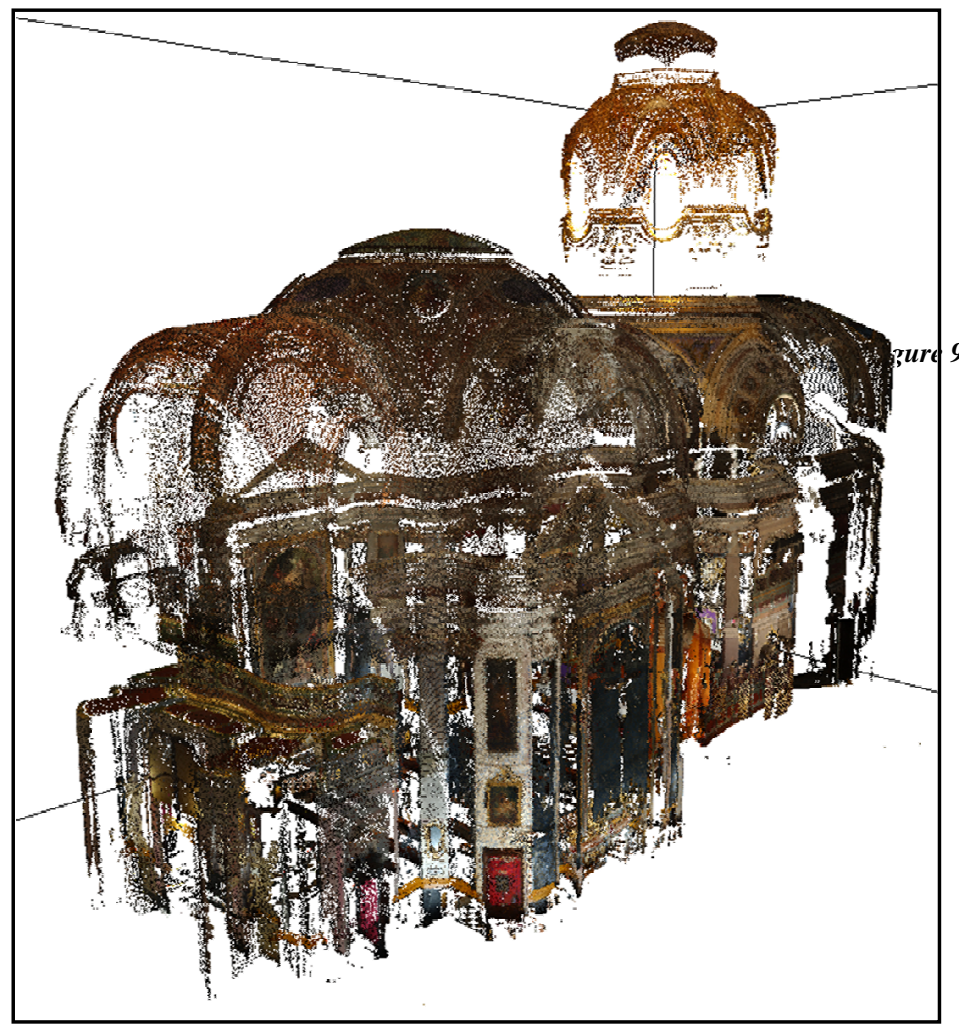

9, 10 - Point cloud images created by the laser scanner

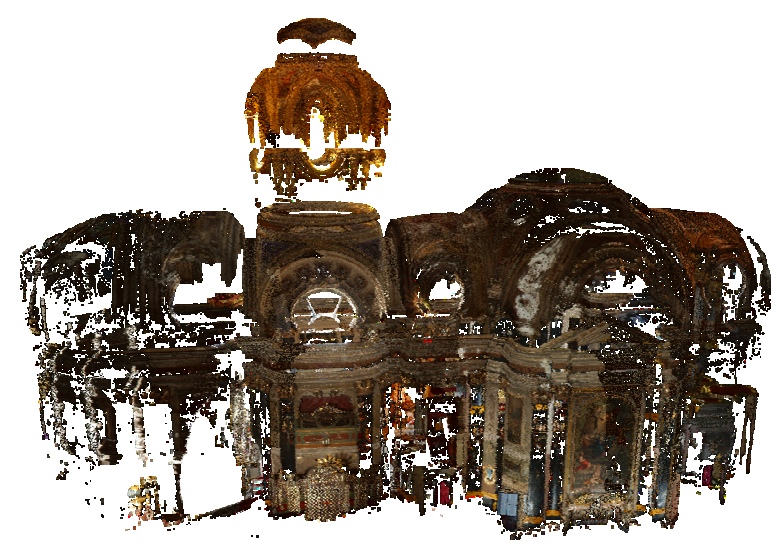


Interviews have been conducted by technicians and professionals, asking information about their use of tools for the calculation and quantification of the restoration work on complex surfaces and developed in three dimensions. Most of them now in fact are using tools very approximate, acting on $2 \mathrm{D}$ models. By simply multiplying by correction factors the interested surface areas applied to a curved surface projected on the plane, the errors that occurr are significant and the calculations are inaccurate. Such evaluation of the measure of the curved surface areas cause errors in economic evaluation, that can be unacceptable especially in the case of construction yards of relevant importance. (Figure11)

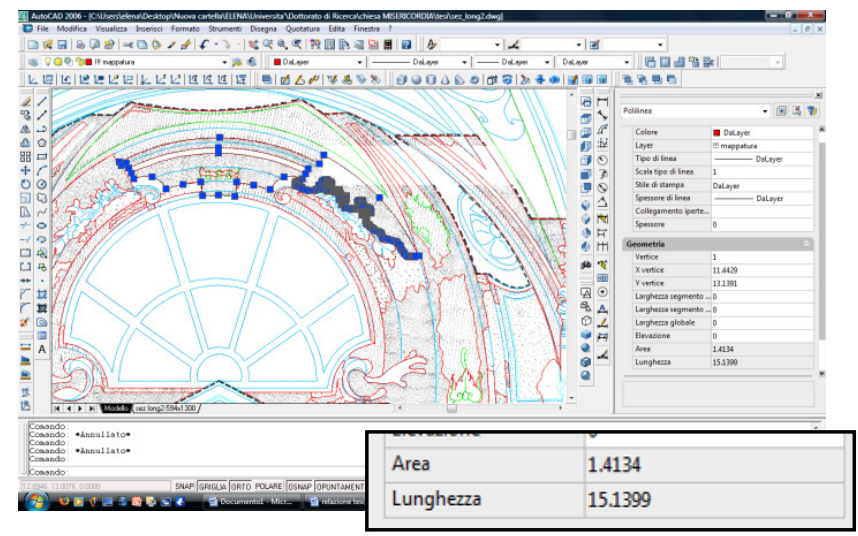

Figure 11 - Vectorization of the degradation mapping
On the so created model it has been tested the magnitude of the errors that arise from the use of simplified systems in the evaluation of areas placed on vaulted and non linear surfaces. As a test is has been considered the simple case of a hemisphere, this being the geometry closer to the case of a curved ceiling typical of architectonic halls It follows that a simple use of the computations carried out on 2D projections can be taken neither as an absolute, nor as a relative reference It is therefore necessary an exact evaluation of the curved surfaces (Figure12); for such a computation shall be very useful those tools that use very accurate computational methods but are at the same time economically sustainable also with respect

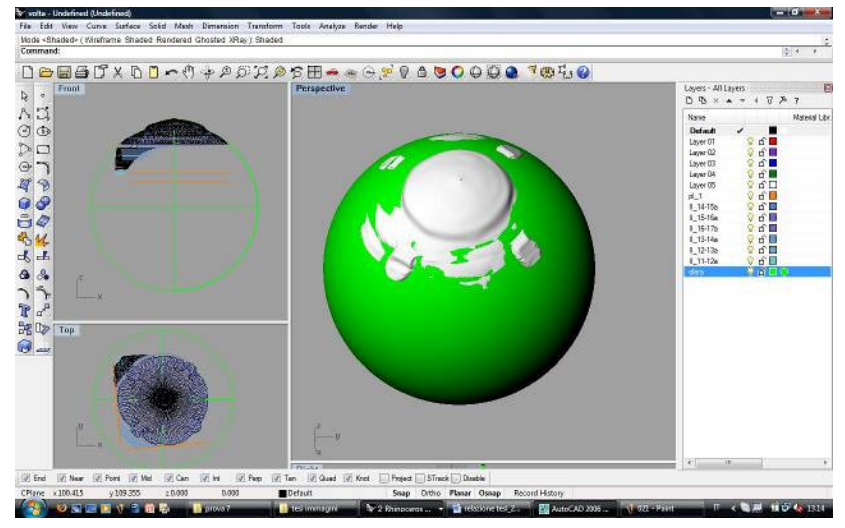

Figure 12 - Model we started from the point cloud which was followed by their interpolation

Figure 13 - contour lines with a pitch of $10 \mathrm{~cm}$, useful to create a "virtual surface" by the laser scanner

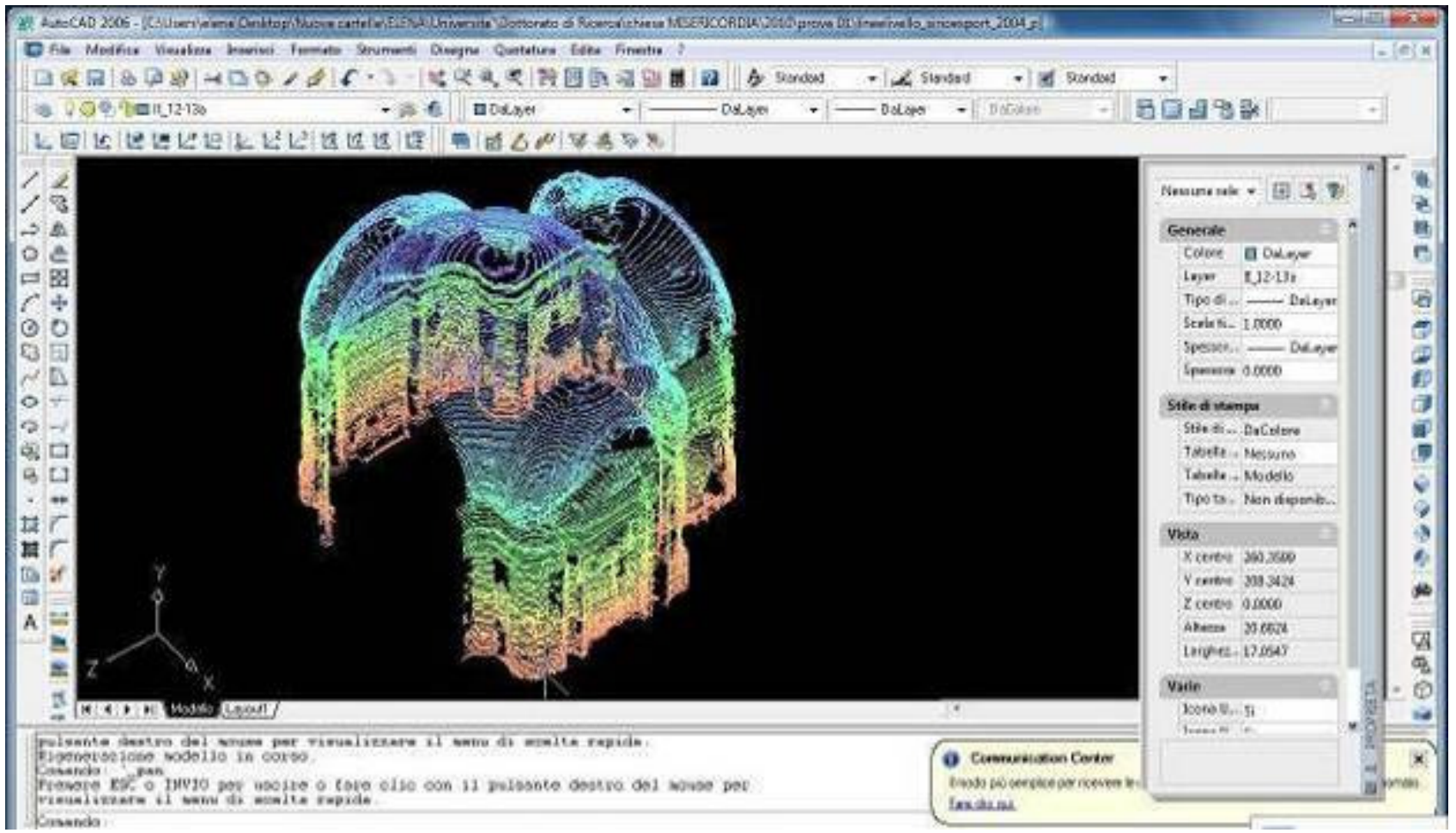


To create the model we started from the point cloud which was followed by their interpolation by means of the Sir-IO software, developed for managing data geomatics. With this software it is possible to get contour lines with a pitch of $10 \mathrm{~cm}$, (Figure13) useful to create a "virtual surface" as close to reality as possible. to the resources of a medium sized yard. By analyzing the results, it can be inferred that most of the technicians are very concerned by the possibility of working on a dynamic threedimensional model that can provide accurate data, but the fact is that most of them still work on two-dimensional media.

Finally, it emerged the need of a three-dimensional digital model that can be used, even just for the communication to the "general public", which is increasingly interested in the restoration sites and their evolution. This tool would be extremely useful to document and to store the life story of the architectural "good".

The activity of mapping the degradation of a surface by acting directly on the three-dimensional solid picture results in 3D polylines that with the actual information tools are difficult to be used by the technicians operating on the yard.

\section{CONCLUSIONS}

During the research, which had to struggle with quite a lot of critical aspects, there occurred some problems that should be considered as central for future developments. They will drive the mainlines for the refinement of software and application technologies, but it must be remembered that, first of all, the direct experience and the validation with practical case studies must be absolutely taken into account.

This research has demonstrated that are the real practical needs that give the input to the development of new theories. Only a direct presence in contact with the reality of the yard can provide the correct pushes for the creation of new tools, even theoretical, from which depends the future of an integrated knowledge, in a society where operators and engines increasingly will find points of agreement.

In conclusion, the experience made and the reflections on the achievements allowed to compare digital techniques of representation for architecture and territory and to prepare methods for the study and for the management of data at different scale: on the basis of the outcomes and of research directions for the future, it has paved the way to thinking useful to the implementation of the method and to the management of the graphic results, both in terms of contents and purely disciplinary.

\section{REFERENCES}

Eros Agosto, Secondino Coppo, Anna Osello, Fulvio Rinaudo, Survey And Representation Methodologies In Teaching Experience, in International Archives of the photogrammetry, remote sensing and spatial information sciences, 2005, pp. 5, ,Vol. Xxxvi-5/C34.

BERALDIn e Marco GAIANI, Valutazioni delle prestazioni di sistemi di acquisizione tipo 3D active-vision: alcuni risultati, in "DDD rivista trimestrale di Disegno digitale e design", Poli Design editore, Anno 2, n. 5 Gen-mar 2003, pagg. 115-128.
Carlo Blasi, Eva Coisson, La fabbrica del Duomo di Parma. Stabilità, rilievi e modifiche nel tempo. Editore Grafiche Step, Parma 2006.

Maurizio Bocconcino, Elena Marchis, Paolo PiUMATti, Marco VITALI, INTEGRATION OF DIGITAL TECHNIQUES FOR Three-dimensional survey: the case study of the baroque church of "San Giovanni Decollato" in: "The CIPA International Archives for Documentation of Cultural Heritage, editor in chief: Yutaka Takase" , 22nd CIPA Symposium Digital Documentation, Interpretation \& Presentation of Cultural Heritage, Kyoto (Japan) 11-15 ottobre 2009.

Valentina BONORA, Antonia SPANò, Strutture voltate: rilievo laser scanning e modellazione delle geometrie, in Atti del Workshop "Tecnologie per Comunicare l'Architettura", Ancona, 20-21-22 maggio 2004.

Leandro BornAz, Sergio DEQUAL, The solid image: a new concept and its applications. In: "The International Archives of the Photogrammetry, Remote Sensing and Spatial Information Sciences", Ancona 2003, Vol. XXXIV, Part 5/W12, pp. 78-82.

Fausto BREvi, Nicolò CECCARElli, Marco GAIANI, Il cantiere di restauro visualizzato, in "Disegnare idee immagini" n. 29/2004, pp.64-79.

Filiberto Chiabrando, Francesco Nex, Dario Piatti, Fulvio RINAUDO, Il rilievo metrico della Chiesa della Misericordia di Torino a supporto del cantiere di restauro. In: "Bollettino della Società Italiana di fotogrammetria e topografia", 2008, Vol. 1, pp 61-82.

Alfonso IPPOLITo, La modellazione delle superfici murarie del Tempio del Divo Claudio a Roma in "Disegnare idee immagini" n. 38/2009, pp.76-85.

Andrea Lingua, Paolo Piumatti, Fulvio Rinaudo, Digital photogrammetry: a standard approach to cultural eritage survey, in "The International Archives of the Photogrammetry, Remote Sensing and Spatial Information Sciences", Ancona 2004, Italy, Vol. XXXIV, Part 5/W12, pp. 210-215.

Andrea Lingua, Paolo Piumatti, Fulvio Rinaudo, Digital photogrammetry: a standard approach to cultural eritage survey, in: "The international archives of the photogrammetry, remote sensing and spatial information sciences, International Society for Photogrammetry and Remot", Ancona, 2003, pp. $210-215$.

Massimiliano Lo Turco, Paolo Piumatti, Tecniche integrate per il rilievo ed il progetto: immagine digitale e modello virtuale a confronto, in: Il disegno di luoghi e mercati a Torino, Secondino CoPPO, Anna OsELlo, Celid, Torino, 2006.

Marco GAIANI, Strategie di rappresentazione digitale: modelli per la conservazione e il restauro, in "Quaderni Centro Ricerche Informatiche per i beni Culturali", Scuola Normale di Pisa, n. X, 2000, pagg. 47-69.

N. Milella, M. Zonno, A. Lerario, Il rilievo digitale dei beni architettonici., http://fabrica.ba.cnr.it/.

Chiara VernIzZI, Considerazioni sul rilevamento per la valutazione strutturale: le volte della navata centrale del Duomo di Parma, in "Disegnare idee immagini" n. 35/2007, pp.74-85. 